\title{
Modulation of Myocardial Stiffness by $\beta$-Adrenergic Stimulation - Its Role in Normal and Failing Heart
}

\author{
I. FALCÃO-PIRES ${ }^{1 *}$, A. P. FONTES-SOUSA ${ }^{1,2^{*}}$, L. LOPES-CONCEIÇÃO $^{1}$, \\ C. BRÁS-SILVA ${ }^{\mathbf{1 , 3}}$, A. F. LEITE-MOREIRA ${ }^{1}$ \\ *Both authors equally contributed to the work presented in this article.
}

${ }^{1}$ Department of Physiology and Cardiothoracic Surgery, Faculty of Medicine, University of Porto, Porto, Portugal, ${ }^{2}$ Laboratory of Pharmacology and Neurobiology/UMIB, Institute of Biomedical Sciences of Abel Salazar (ICBAS), University of Porto, Porto, Portugal, ${ }^{3}$ Faculty of Nutrition and Food Sciences, University of Porto, Porto, Portugal

Received September 21, 2010

Accepted March 18, 2011

On-line May 16, 2011

\section{Summary}

The acute effects of $\beta$-adrenergic stimulation on myocardial stiffness were evaluated. New-Zealand white rabbits were treated with saline (control group) or doxorubicin to induce heart failure (HF) (DOXO-HF group). Effects of isoprenaline $\left(10^{-10}-10^{-5} \mathrm{M}\right)$, a non-selective $\beta$-adrenergic agonist, were tested in papillary muscles from both groups. In the control group, the effects of isoprenaline were also evaluated in the presence of a damaged endocardial endothelium, atenolol ( $\beta_{1}$-adrenoceptor antagonist), ICI-118551 ( $\beta_{2}$-adrenoceptor antagonist), KT-5720 (PKA inhibitor), L-NNA (NO-synthase inhibitor), or indomethacin (cyclooxygenase inhibitor). Passive length-tension relations were constructed before and after adding isoprenaline $\left(10^{-5} \mathrm{M}\right)$. In the control group, isoprenaline increased resting muscle length up to $1.017 \pm 0.006 \mathrm{~L} / \mathrm{L}_{\max }$. Correction of resting muscle length to its initial value resulted in a $28.5 \pm 3.1 \%$ decrease of resting tension, indicating decreased muscle stiffness, as confirmed by the isoprenaline-induced right-downward shift of the passive lengthtension relation. These effects were modulated by $\beta_{1^{-}}$and $\beta_{2^{-}}$ adrenoceptors and PKA. In DOXO-HF group, the effect on myocardial stiffness was significantly decreased. We conclude that $\beta$-adrenergic stimulation is a relevant mechanism of acute neurohumoral modulation of the diastolic function. Furthermore, this study clarifies the mechanisms by which myocardial stiffness is decreased.

\section{Key words}

$\beta$-adrenergic stimulation • Diastolic function • Myocardial stiffness

- Heart failure

\section{Corresponding author}

A. F. Leite-Moreira, Department of Physiology and Cardiothoracic Surgery, Faculty of Medicine, Alameda Professor Hernâni Monteiro, 4200-319 Porto, Portugal. Fax: +351 225513646. E-mail: amoreira@med.up.pt

\section{Introduction}

Although the evaluation of the myocardial function of the heart is usually focused on its chronotropic and inotropic state, the assessment of the diastolic response to pharmacological intervention is presently recognized as one of great clinical relevance. The most important mechanisms that increase resistance to left ventricular (LV) filling and consequently, lead to diastolic dysfunction and diastolic heart failure (HF), are impaired cardiac relaxation and increased stiffness (LeiteMoreira 2006).

Beta-adrenergic stimulation is an important physiological mechanism for enhancing cardiac performance during increased circulatory demands. The activation of these receptors on cardiac myocytes initiates signalling pathways that increase contractility and accelerate relaxation. Nowadays, three $\beta$-adrenoceptor subtypes have been identified, $\beta_{1^{-}}, \beta_{2^{-}}$, and $\beta_{3^{-}}$ adrenoceptor. Mammalian cardiac myocytes express predominantly $\beta_{1}$-adrenoceptor, in a range from $60-80 \%$ depending on the species, and in a less extent $\beta_{2}$-adrenoceptor. These receptors modulate systolic and 
diastolic functions in very different ways (for review see Brodde et al. 2006). The effects of $\beta$-adrenergic stimulation are partially mediated by cAMP-dependent protein kinase A (PKA) that subsequently phosphorylates several intracellular substrates, including membrane channels and myofilamentary proteins such as actin and myosin. Fast changes in intracellular $\mathrm{Ca}^{2+}$-handling are thought to be largely responsible for the positive inotropy and lusitropy. Some of the mechanisms underlying $\mathrm{Ca}^{2+}$ homeostasis and responsible for increasing lusitropy are the phosphorylation of: 1) phospholamban, enhancing $\mathrm{Ca}^{2+}$ reuptake into the sarcoplasmatic reticulum (Bers and Guo 2005), 2) troponin I (TnI), decreasing myocardial calcium $\left(\mathrm{Ca}^{2+}\right)$ sensitivity on the thin filaments by increasing the rate at which $\mathrm{Ca}^{2+}$ dissociates from troponin C (TnC) (Robertson et al. 1982, Wattanapermpool et al. 1995, Zhang et al. 1995, Johns et al. 1997, Fentzke et al. 1999) and 3) myosin binding protein-C (MyBP-C), accelerating crossbridge cycling and increasing myofibrillar ATPase activity (Gruen et al. 1999, Kunst et al. 2000). These mechanisms, which can be modulated by $\beta$-adrenergic stimulation, may lead to a faster rate of myofibrillar relaxation thereby shortening twitch duration.

Besides relaxation, myocardial stiffness is a major determinant of diastolic function (Leite-Moreira 2006). We previously demonstrated acute changes of myocardial stiffness after myocardial exposure to several neurohumoral agents like endothelin-1 (Leite-Moreira et al. 2003), angiotensin II (Leite-Moreira et al. 2006), urotensin II (Fontes-Sousa et al. 2007) and adrenomedullin (Fontes-Sousa et al. 2009). In the same way, nitric oxide (NO) decreases myocardial stiffness (Paulus et al. 1994, Shah and MacCarthy 2000). Furthermore, diastolic dysfunction induced by excessive afterload was attenuated by $\beta$-adrenergic stimulation, highlighting the lusitropic effects of this neurohumoral system (Leite-Moreira et al. 2001). However, the underlying mechanisms remain unexplored.

In this context, the present study aims at exploring the effects of $\beta$-adrenergic stimulation on myocardial passive properties, investigating: 1) the effects on myocardial stiffness in healthy rabbits and its underlying mechanisms, and 2) whether this effect is preserved in an animal model of HF.

\section{Methods}

This study was performed in New-Zealand
White rabbits (Oryctolagus cuniculus) and complied with the Guide for the Care and Use of Laboratory Animals published by the US National Institutes of Health (NIH Publication No 85-23, Revised 1996).

\section{Heart Failure Model}

A well-documented regimen was used for the induction of $\mathrm{HF}$ secondary to doxorubicin toxicity (Arnolda et al. 1985). Adult male New Zealand White rabbits received doxorubicin (DOXO-HF) via a marginal ear vein by bolus injection $(1 \mathrm{mg} / \mathrm{kg})$ twice a week during 8 weeks $(n=9)$ followed by a washout period of one week. This model culminates with a depressed myocardial function compatible with dilated cardiomyopathy, as we previously demonstrated by echocardiography (Bras-Silva et al. 2006). Control rabbits $(n=39)$ received vehicle $(0.9 \%$ saline $)$ in equivolumetric doses during the same period.

\section{Experimental preparation}

Isometric and isotonic contractions were analyzed in papillary muscles isolated from the right ventricle of control $(n=73)$ and DOXO-HF $(n=9)$ rabbits, one week after the last administration of doxorubicin or saline. Male rabbits $(2.3 \pm 0.1 \mathrm{~kg}, \mathrm{n}=48)$ were anesthetized with intravenous sodium pentobarbital (25 mg. $\left.\mathrm{kg}^{-1}\right)$. A left thoracotomy was performed, beating hearts were quickly excised and immersed in a modified KrebsRinger solution at $35{ }^{\circ} \mathrm{C}$, with $5 \%$ Newborn Calf Serum and with cardioplegic 2,3-butanedione monoxime (BDM, $3 \%$ ), a selective inhibitor of cross-bridge cycling to stop mechanical activity and preserve myocardial metabolism. The modified Krebs-Ringer solutions contained (in $\mathrm{mM}$ ): $98 \mathrm{NaCl}, 4.7 \mathrm{KCl}, 2.4 \mathrm{MgSO}_{4} .7 \mathrm{H}_{2} \mathrm{O}, 1.2 \quad \mathrm{KH}_{2} \mathrm{PO}_{4}$, 4.5 glucose, $1.8 \mathrm{CaCl}_{2} .2 \mathrm{H}_{2} \mathrm{O}, 17 \mathrm{NaHCO}_{3}, 15 \mathrm{C}_{3} \mathrm{H}_{3} \mathrm{O}_{3} \mathrm{Na}$, $5 \mathrm{CH}_{3} \mathrm{COONa}$ and 0.003 prazosin). Prazosin, an $\alpha$-adrenergic antagonist, was used to prevent $\alpha$-adrenergic mediated effects. The solutions were in equilibrium with $95 \% \mathrm{O}_{2}$ and $5 \% \mathrm{CO}_{2}$, to obtain a $\mathrm{pH}$ between 7.38-7.42.

The right ventricle was opened and papillary muscles were isolated by first dividing the chordae tendinae at the muscle tip and then freeing the muscle base and a small amount of surrounding myocardium from the ventricular wall. The time from thoracotomy to dissection was $\sim 3$ min and only long, thin, uniformly cylindrical muscles were used.

After dissection, papillary muscles $(n=82$, length: $3.8 \pm 0.1 \mathrm{~mm}$, weight: $3.2 \pm 0.2 \mathrm{mg}$, preload: $3.6 \pm 0.1 \mathrm{mN}$ ) were mounted vertically in a $10 \mathrm{ml}$ plexi 
glass organ bath containing the aforementioned KrebsRinger solution. The lower muscular end was fixed in a phosphorbronze clip and the upper tendinous end was attached to an electromagnetic length-tension transducer (University of Antwerp, Belgium) (Brutsaert et al. 1971).

Preload was initially set between 3 to $4 \mathrm{mN}$ according to muscle dimensions. The preparations were stimulated at $0.6 \mathrm{~Hz}$ with a voltage of $10 \%$ above threshold (typically $30-60 \mathrm{mV}$ ) by rectangular pulses of $5 \mathrm{~ms}$ duration through two platinum electrodes arranged longitudinally alongside the entire muscle. After $20 \mathrm{~min}$, bathing solutions were replaced by corresponding KrebsRinger solutions without BDM and the muscle started to contract. One hour later, bathing solution was replaced by corresponding serum-free Krebs-Ringer solution. During the next 2 hours the muscles stabilized. Finally, the muscles were stretched to a muscle length at which active force development was maximal $\left(\mathrm{L}_{\max }\right)$. During the experiment, changes in diastolic muscle length and muscle shortening were measured by the isotonic transducer. Protocols were initiated after obtaining two similar isotonic and isometric control twitches separated by a $10 \mathrm{~min}$ interval. Throughout the entire experiment, the temperature was set at $35^{\circ} \mathrm{C}$.

At the end of the experiment the muscles were removed, lightly blotted and then weighed. Muscle crosssectional area was calculated by dividing the weight of the muscle by its length at $\mathrm{L}_{\max }$. A cylindrical shape and a specific density of 1.0 were assumed. Muscle tension was then expressed as force normalized per cross-sectional area $\left(\mathrm{mN} / \mathrm{mm}^{2}\right)$.

\section{Experimental protocols}

Effects of increasing concentrations of isoprenaline (ISO, $10^{-10}$ to $10^{-5} \mathrm{M}$ ), a non-selective $\beta$-adrenergic agonist, were studied in papillary muscles from the control $(n=13)$ and DOXO-HF $(n=9)$ groups. In another set of papillary muscles from the control group, myocardial effects of increasing concentrations of isoprenaline $\left(10^{-10}\right.$ to $\left.10^{-5} \mathrm{M}\right)$ were evaluated in the presence of (i) atenolol (selective $\beta_{1}$-adrenoceptor antagonist, $2 * 10^{-5} \quad \mathrm{M}, \quad \mathrm{n}=8$ ), (ii) ICI 118,551 hydrochloride (ICI, selective $\beta_{2}$-adrenoceptor antagonist, $10^{-6} \mathrm{M}, \mathrm{n}=8$ ) or (iii) KT-5720 (KT, inhibitor of protein kinase A (PKA), $10^{-6} \mathrm{M}, \mathrm{n}=6$ ). Considering that the modulation of myocardial stiffness by other neurohumoral agents require an intact endocardial endothelium (EE) (Bras-Silva and Leite-Moreira 2006) and that DOXO-HF model presents functional evidences of EE dysfunction (Bras-Silva et al. 2006), the same range of isoprenaline concentrations were studied in papillary muscles from control rabbits after (iv) damaging the EE (TRX, n=12) or in the presence of (v) NG-nitro-Larginine (L-NNA, nitric oxide synthase inhibitor, $10^{-5} \mathrm{M}$, $\mathrm{n}=7$ ) or (vi) indomethacin (INDO, cyclooxygenase inhibitor, $10^{-5} \mathrm{M}, \mathrm{n}=7$ ), two important EE mediators. EE was damaged by briefly ( $1 \mathrm{~s})$ exposing the isolated papillary muscle to a weak solution $(0.5 \%)$ of the detergent Triton X-100 (Brutsaert et al. 1988, LeiteMoreira and Bras-Silva 2004).

The concentrations of atenolol, ICI 118,551, KT, NG-nitro-L-arginine and indomethacin were selected on the basis of several studies showing that their physiological effects on myocardial tissue or whole heart preparations are exerted by concentrations in the micromolar range (Mohan et al. 1995, Haikala et al. 1997, Varma et al. 1999, Bras-Silva et al. 2008, Faucher et al. 2008).

Most of the substances were dissolved in a Krebs-Ringer solution bath before the addition of isoprenaline, except for atenolol, which was added to the initial Krebs-Ringer solution at the final concentration. Muscle twitches were recorded after a stable response was obtained, typically 20 minutes following addition of the antagonists/inhibitors to the muscle preparation. After that, isoprenaline was added cumulatively without any washout in between, with a maximal effect occurring approximately 3-5 min after the latest addition.

In a last set of papillary muscles from control rabbits, passive length-tension relations were constructed before and after a single concentration of isoprenaline $\left(10^{-5} \mathrm{M}, \mathrm{n}=6\right)$. It consisted in decreasing the passive tension of the muscle in a stepwise manner $(10 \%)$, with an interval between each reduction of $\sim 4 \mathrm{~min}$ until reaching $40 \%$ of its initial passive tension. After restoring passive tension to its initial value, isoprenaline was added to the bath. Five minutes later, another passive tension reduction protocol was performed.

Since all the experiments were performed in the presence of prazosin $(3 \mu \mathrm{M})$, as described above, we evaluated its effects on myocardial function in papillary muscles from control animals $(\mathrm{n}=6$, included in the total number given above). Prazosin did not change myocardial performance (data not shown).

Papillary muscles obtained from the same rabbit were used for different experimental protocols. All chemicals were obtained from Sigma Chemical Co, St Louis, Mo, except ICI 118,551 hydrochloride that was 
obtained from Tocris Bioscience, Missouri, USA.

Most of the stock solutions, including isoprenaline, were prepared in distilled water and stored as frozen aliquots at $-20{ }^{\circ} \mathrm{C}$ until use. KT ester was dissolved in DMSO (less than $0.1 \%$ in the bath) and water. No statistically significant differences were observed between control experiments, made in the absence or in the presence of the solvent at the maximal concentrations used $(0.5 \%, \mathrm{v} / \mathrm{v})$. The $\mathrm{pH}$ of the superfusion solution did not change following addition of the drugs to the muscle preparations.

\section{Data analysis}

Isotonic and isometric twitches were converted online to digital data with a sampling frequency of 1000 $\mathrm{Hz}$ (Daqbook/120, IOTech Inc. Cleveland, Ohio, USA) and analyzed with specific software (University of Antwerp, Belgium).

Selected parameters included: active tension (AT, $\mathrm{mN} / \mathrm{mm}^{2}$ ), maximum velocities of tension rise $\left(\mathrm{dT} / \mathrm{dt}_{\max }, \mathrm{mN} / \mathrm{mm}^{2}\right)$ and decline $\left(\mathrm{dT} / \mathrm{dt}_{\min }, \mathrm{mN} / \mathrm{mm}^{2} / \mathrm{s}^{1}\right)$, peak isotonic shortening ( $\mathrm{PS}, \% \mathrm{~L}_{\max }$ ), maximum velocities of shortening $\left(\mathrm{dL} / \mathrm{dt}_{\max }, \mathrm{L}_{\max } \mathrm{s}^{-1}\right)$ and lengthening ( $\mathrm{dL} / \mathrm{dt}_{\min }, \mathrm{L}_{\max } \mathrm{s}^{-1}$ ), time to half-relaxation (tHR, ms), and time to active tension (tAT, ms), resting tension $\left(\mathrm{RT}, \mathrm{mN} / \mathrm{mm}^{2}\right)$, and muscle length $\left(\mathrm{L}, \mathrm{L} / \mathrm{L}_{\max }\right)$.

In the various protocols, results are given as percent change from baseline. For the parameters that are expressed as negative values (e.g. $\mathrm{dT} / \mathrm{dt}_{\text {min }}$ ), such percent change refers to the absolute values. When a pharmacological inhibitor was used or the EE damaged, the term baseline refers to the experimental condition in presence of those inhibitors or after EE damaging, before the addition of isoprenaline.

An exponential curve was fitted to passive length-tension relations either before or after isoprenaline administration $\left(10^{-5} \mathrm{M}\right)$ to calculate muscle stiffness constant $\left(\mathrm{K}_{\mathrm{c}}\right)$.

\section{Statistical methods}

Values are means \pm S.E.M and $n$ represents the number of experiments. Statistical significance was determined using analysis of variances (ANOVA) and Student-Newman-Keuls for pairwise multiple comparisons. $\mathrm{P}<0.05$ was accepted as significant.

\section{Results}

Mean values of the morphological and contractile parameters in papillary muscles from the control group $(\mathrm{n}=73)$ and from the DOXO-HF group $(n=9)$ are shown in Table 1. Morphometric characteristics and baseline performance of rabbit papillary muscles from control group were similar within all the experimental protocols. Compared with control group, papillary muscles from DOXO-HF rabbits showed lower baseline performance, indicating contractile dysfunction.

Table 1. Mean values of the morphologic and contractile parameters in papillary muscles from the control and doxorubicin-induced heart failure (DOXO-HF).

\begin{tabular}{lcc}
\hline Parameter & $\begin{array}{c}\text { Control } \\
\text { group }(\mathbf{n}=\mathbf{7 3})\end{array}$ & $\begin{array}{c}\text { DOXO-HF } \\
\text { group (n=9) }\end{array}$ \\
\hline Length $(\mathrm{mm})$ & $3.9 \pm 0.2$ & $3.9 \pm 0.2$ \\
Weight $(\mathrm{mg})$ & $3.1 \pm 0.2$ & $4.2 \pm 0.6^{*}$ \\
Preload $(\mathrm{mN})$ & $3.8 \pm 0.1$ & $2.8 \pm 0.4$ \\
$A T\left(\mathrm{mN} / \mathrm{mm}^{2}\right)$ & $27.6 \pm 2.0$ & $7.2 \pm 1.9^{*}$ \\
$d T / d t_{\max }\left(\mathrm{mN} / \mathrm{mm}^{2} / \mathrm{s}\right)$ & $197.4 \pm 14.5$ & $61.6 \pm 11.2^{*}$ \\
$d T / d t_{\min }\left(\mathrm{mN} / \mathrm{mm}^{2} / \mathrm{s}\right)$ & $-149.2 \pm 9.2$ & $-54.9 \pm 9.2^{*}$ \\
$t H R(\mathrm{~ms})$ & $382.9 \pm 10.1$ & $265.4 \pm 28.6^{*}$ \\
$t A T(\mathrm{~ms})$ & $239.1 \pm 5.6$ & $175.9 \pm 17.8^{*}$ \\
$P S\left(\% L_{\max }\right)$ & $12.9 \pm 0.6$ & $5.6 \pm 0.7^{*}$ \\
$d L / d t_{\max }\left(L_{\max } / s\right)$ & $1.0 \pm 0.05$ & $0.5 \pm 0.1^{*}$ \\
$d L / d t_{\min }\left(L_{\max } / \mathrm{s}\right)$ & $-3.7 \pm 0.2$ & $-1.3 \pm 0.2^{*}$ \\
\hline
\end{tabular}

AT: active tension; $d T / \mathrm{dt}_{\max }, \mathrm{dT} / \mathrm{dt}_{\min }$ : maximum velocities of tension rise and decline, respectively; tHR: time to half relaxation; tAT: time to active tension; PS: peak isotonic shortening; $\mathrm{dL} / \mathrm{dt}_{\max }, \mathrm{dL} / \mathrm{dt}_{\min }$ : maximum velocities of shortening and lengthening, respectively. Values are means \pm S.E.M. $P<0.05$ : * vs control group baseline values.

Effects of increasing concentration of isoprenaline on the systolic and diastolic properties of isolated papillary muscles are illustrated in Figures 1 and 2. In the control group with intact EE, increasing concentrations of isoprenaline enhanced both contractility (AT and $\mathrm{dT} / \mathrm{dt}_{\max }$ ) and lusitropy ( $\mathrm{dT} / \mathrm{dt}_{\min }$, tAT and $\mathrm{tHR}$ ). The highest concentration of isoprenaline $\left(10^{-5} \mathrm{M}\right)$ increased AT by $107.4 \pm 7.9 \%, \mathrm{dT} / \mathrm{dt}_{\max }$ by $276.2 \pm 27.6 \%$ and $\mathrm{dT} / \mathrm{dt}_{\min }$ by $182.1 \pm 16.1 \%$ (p<0.05, Fig. 1a). On the contrary, tAT and tHR decreased by $36.8 \pm 3.5 \%$ and $33.0 \pm 3.2 \%$, respectively ( $<00.05$, Fig. 1 b). Concerning the diastolic properties of the myocardium, besides increasing relaxation rate $\left(\mathrm{dT} / \mathrm{dt}_{\min }\right)$, decreasing time to half relaxation (tHR) and promoting an earlier onset of relaxation (tAT), isoprenaline progressively increased resting muscle length, at a constant resting tension, up to 
a

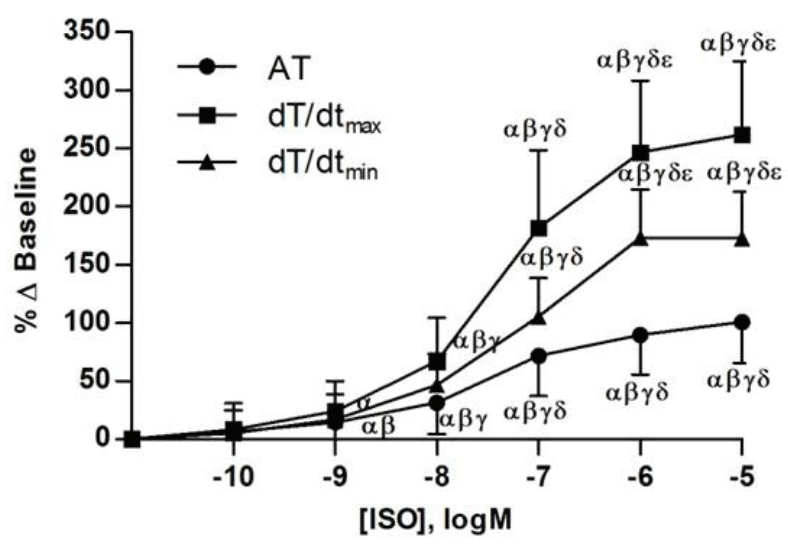

b

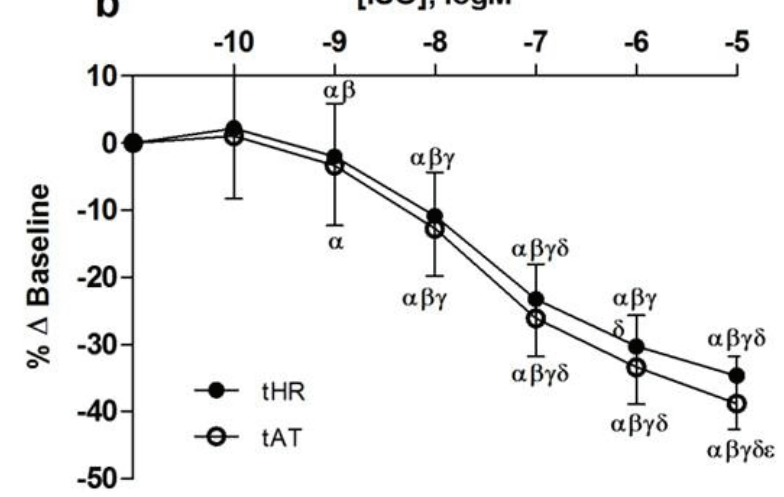

Fig. 1. Effects of increasing concentrations of isoprenaline (ISO, $10^{-10}$ to $10^{-5} \mathrm{M} ; \mathrm{n}=13$ ) on: (a) active tension (AT), maximum velocities of tension rise (dT/dt $\left.t_{\max }\right)$ and decline $\left(\mathrm{dT} / \mathrm{dt}_{\min }\right)$; and (b) time to half-relaxation (tHR) and time to active tension (tAT). Data are means \pm S.E.M. $P<0.05$ : a vs baseline, $\beta$ vs $10^{-10} \mathrm{M}$ ISO, Y vs $10^{-9} \mathrm{M}$ ISO, $\delta$ vs $10^{-8} \mathrm{M}$ ISO, $\varepsilon$ vs $10^{-7} \mathrm{M}$ ISO.

$1.017 \pm 0.006 \mathrm{~L} / \mathrm{L}_{\max }$ (Fig. 2). Correcting final muscle length to its initial value resulted in a $28.5 \pm 3.1 \%$ decrease of RT, without altering other contractile parameters. All these results indicate a decrease in muscle stiffness or, in other words, an increase in muscle distensibility.

This aspect is further explored in Figure 3 where passive length-tension relations at baseline and in the presence of isoprenaline $\left(10^{-5} \mathrm{M}\right)$ are presented. Muscle stiffness constant $\left(\mathrm{K}_{\mathrm{c}}\right)$ acutely decreased from $23.1 \pm 4.1$ to $20.9 \pm 4.0 \quad \mathrm{mN} / \mathrm{mm}^{2} \quad(\mathrm{p}=0.048)$ while no significant changes were observed in the intercept of the stiffness curve (baseline: $4.6^{*} 10^{-10} \pm 1.7^{*} 10^{-9} \mathrm{mN} / \mathrm{mm}^{2}$, ISO: $\left.3.1 * 10^{-9} \pm 2.3 * 10^{-9} \mathrm{mN} / \mathrm{mm}^{2}, \mathrm{p}=0.44\right)$.

As referred previously, the effects of isoprenaline were also tested in the presence of antagonists/inhibitors, and none of them modified per se baseline muscle performance. Selective antagonism of $\beta_{1}$-adrenoceptor rightward shifted the concentrationresponse curve of isoprenaline concerning its positive inotropic (AT) and lusitropic $\left(\mathrm{dT} / \mathrm{dt}_{\min }\right)$ effects. On the other hand, neither antagonism of $\beta_{2}$-adrenoceptor nor PKA inhibition altered these effects (data not shown). Regarding the diastolic properties of the myocardium, interestingly, antagonism of $\beta_{1}$-adrenoceptor and PKA inhibition significantly decreased isoprenaline effects on muscle length $\left(\mathrm{L} / \mathrm{L}_{\max }, \quad\right.$ Fig. $\left.4 \mathrm{a}\right) . \quad \beta_{2}$-adrenoceptor antagonism abolished this effect as no difference in $\mathrm{L} / \mathrm{L}_{\max }$ was observed before and after adding the maximal concentration of isoprenaline (Fig. 4a). These findings together with the distinct EC50 values for positive inotropism $(0.14 \pm 0.09 \mu \mathrm{M}$, Figure 1a) and decreased stiffness ( $879 \pm 6 \mu \mathrm{M}$, Fig. $2 \mathrm{~b}$ ) of isoprenaline highlight the dissociation between its effects on myocardial contractility and stiffness.

In DOXO-HF group, increasing concentrations of isoprenaline promoted higher percentage of variation mostly because the baseline muscle performance was significantly lower (Table 1). Maximal concentration of isoprenaline increased AT by $380.2 \pm 83.4 \%, \mathrm{dT}^{\mathrm{d}} \mathrm{dt}_{\max }$ by $513.6 \pm 95.2 \%, \mathrm{dT} / \mathrm{dt}_{\min }$ by $558.9 \pm 124.0 \%$ and decreased tAT by $23.8 \pm 4.0 \%$ and tHR by $24.4 \pm 3.8 \%(\mathrm{p}<0.05)$. Furthermore, isoprenaline-induced increase of distensibility was attenuated in DOXO-HF group (1.004 \pm 0.002 L/L $\mathrm{L}_{\max }$, Fig. 4b).

In the control group, we additionally investigated the contribution of $\mathrm{EE}$ and its mediators on the increase of distensibility induced by isoprenaline. Neither its removal, nor the inhibition of prostaglandins (INDO) nor NO (L-NNA) release significantly altered the inotropic or lusitropic response to isoprenaline (TRX: increased AT by $209.4 \pm 54.8 \%, \mathrm{dT} / \mathrm{dt}_{\max }$ by $458.2 \pm$ $98.8 \%, \mathrm{dT} / \mathrm{dt}_{\min }$ by $268.1 \pm 51.8 \%$ and decreased tAT by $36.0 \pm 2.9 \%$, and tHR by $30.4 \pm 2.4 \%$, INDO: increased AT by $108.9 \pm 16.0 \%, \mathrm{dT} / \mathrm{dt}_{\max }$ by $238.7 \pm 31.9 \%, \mathrm{dT} / \mathrm{dt}_{\min }$ by $172.5 \pm 18.4 \%$ and decreased tAT by $32.7 \pm 3.2 \%$, and tHR by $30.5 \pm 3.0 \%$, L-NNA: increased AT by $137.6 \pm 66.4 \%, \mathrm{dT}^{2} \mathrm{dt}_{\max }$ by $335.3 \pm 99.8 \%, \mathrm{dT} / \mathrm{dt}_{\min }$ by $251.2 \pm 109.6 \%$ and decreased tAT by $46.6 \pm 4.6 \%$, and tHR by $44.8 \pm 4.4 \%$ ). Additionally, none of these interventions significantly altered the effects of isoprenaline on muscle distensibility (Fig. 4c).

The response of passive muscle length and tension to the maximal concentration of isoprenaline $\left(10^{-5} \mathrm{M}\right)$ alone and in all experimental protocols is summarised in Figure 5. Only the selective antagonism of $\beta_{1}$-adrenoceptor, $\beta_{2}$-adrenoceptor or the inhibition of 

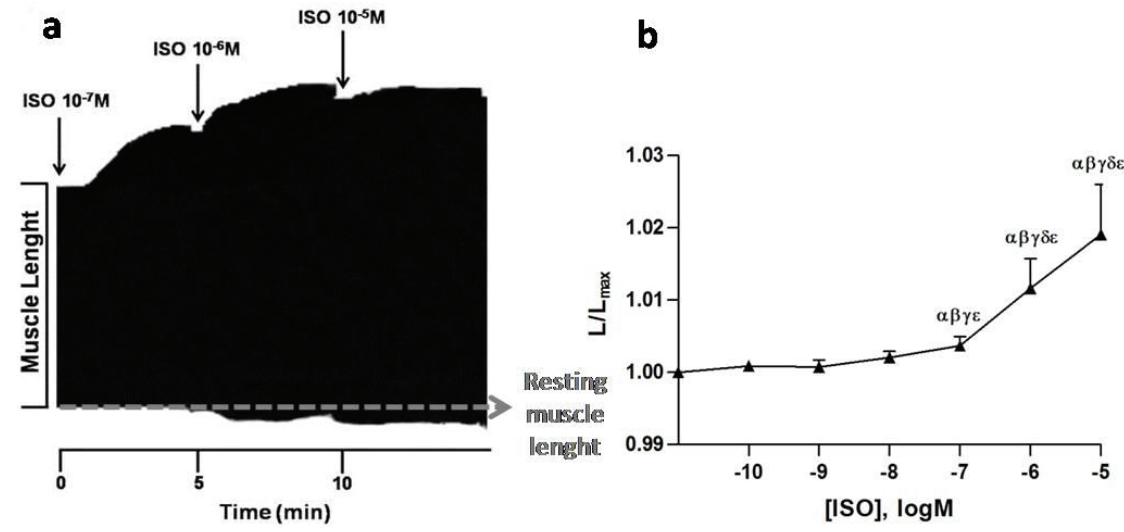

Fig. 2. (a) Representative time band of isotonic contractions of electrically paced papillary muscles contractions. Increasing concentrations of isoprenaline (ISO; $10^{-7}$ $10^{-5} \mathrm{M}$, black arrows) induce a positive inotropic response (illustrated by an increase in muscle shortening with a decrease in systolic length), together with an increase in myocardial distensibility, represented by resting muscle length $\left(L / L_{\max }\right)$, illustrated by a raise in resting muscle length from baseline, gray dotted line); (b) Effects of increasing concentrations of ISO $\left(10^{-10}\right.$ to $10^{-5} \mathrm{M}$; $n=13$ ) on resting muscle length $\left(L / L_{\max }\right)$. Data are means \pm S.E.M. $P<0.05$ : a vs baseline, $\beta$ vs $10^{-10} \mathrm{M}$ ISO, y vs $10^{-9} \mathrm{M}$ ISO, $\delta$ vs $10^{-8} \mathrm{M}$ ISO, $\varepsilon$ vs $10^{-7} \mathrm{M}$ ISO.
PKA markedly reduced the effect of isoprenaline on muscle length, leading to a decrease in passive tension. The acute effect of $\beta$-adrenergic stimulation on muscle length in DOXO-HF animals was significantly decreased when compared with control group.

\section{Discussion}

The myocardial effects of $\beta$-adrenoceptor stimulation by isoprenaline on papillary muscles from healthy and DOXO-HF rabbits were evaluated in this study. Besides the demonstration of the well-documented positive inotropic and lusitropic effects (Bers 2002), the novel finding herein reported was that $\beta$-adrenergic stimulation induces a significant concentration-dependent acute decrease of myocardial stiffness, dependent on the activation of $\beta_{1}, \beta_{2}$-adrenoceptor and PKA. Both the endothelium and the evaluated endothelial mediators, NO and prostaglandins, did not interfere with this effect. Furthermore, this effect was significantly decreased in the presence of HF induced by doxorubicin.

Myocardial function was evaluated in vitro using papillary muscles. This model has the advantage of excluding confounding systemic variables, such as changes in preload, afterload or coronary flow. Specifically in this study, the use of a rabbit model presents many advantages as both $\beta_{1}$ and $\beta_{2}$-adrenoceptors are present in its ventricular myocytes (Marian 2006), and the failing rabbit heart exhibits molecular changes in $\beta$-adrenergic signaling similar to those observed in human HF (Maurice et al. 1999). These characteristics make such species a suitable experimental model to study myocardial passive properties and performance under $\beta$-adrenergic stimulation.

Beta-adrenergic stimulation induced by the sympathetic nervous system plays a pivotal role in the regulation of myocardial structure and function in the normal and failing heart. Several studies focusing on the effects of $\beta$-adrenergic stimulation support that crossbridge cycle and several other phosphorylation events are the major determinants of the intrinsic rate of myocardial relaxation (Bronzwaer and Paulus 2005). On the other hand, cardiac hypertrophy and failure are also characterized by an overall loss of sensitivity to $\beta$-adrenoceptor stimulation (Bristow et al. 1986, Steinberg 1999). However, the effects of $\beta$-adrenergic stimulation on other major determinants of diastolic function, such as the passive properties, like myocardial stiffness, remained to be clarified in both conditions.

We observed that $\beta$-adrenoceptor stimulation decreases myocardial stiffness through both $\beta_{1}$ and $\beta_{2}$-AR activation. There has been a tendency to think of $\beta_{1}$ - and $\beta_{2}$-adrenoceptors as being nearly equivalent, at least in terms of their cAMP-mediated effects, but there are important differences. Several studies focusing on the myocardial response to $\beta_{2}$-adrenoceptor stimulation have reported that while there are similar agonist-dependent increases in tension development, the acceleration of relaxation typically seen with $\beta_{1}$-adrenoceptor stimulation is attenuated or absent with $\beta_{2}$-AR stimulation (Xiao et al. 1995). Although our results demonstrate a potential cardiovascular role for $\beta_{2}-\mathrm{AR}$ as an acute modulator of myocardial stiffness, we cannot exclude an additional effect of ICI-118551 on $\beta_{1}$-AR.

In the current study, by using KT, a PKA specific inhibitor (Bishopric et al. 1992, Haikala et al. 1997, Kiehn et al. 1998, Iwai-Kanai et al. 1999), we confirmed that isoprenaline-induced decrease of myocardial stiffness is dependent on the activation of PKA which is consonant with previously published data on the effects of PKA in engineered rat heart tissue (Zimmermann et al. 2002) and human cardiac cells (Borbely et al. 2005, van Heerebeek 


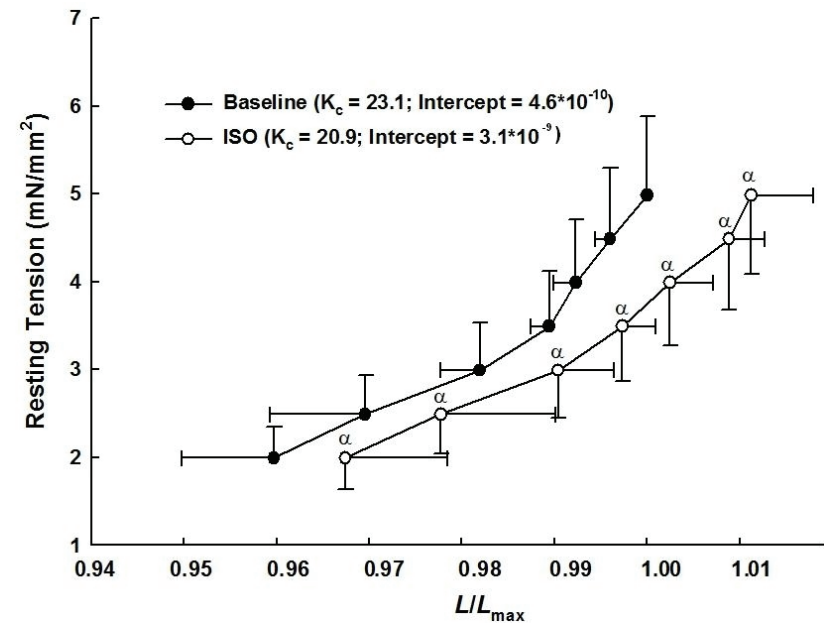

Fig. 3. Passive length-tension relations at baseline $\left(K_{c}=23.1\right.$, Intercept $=4.6 * 10^{-10}$ ) and in the presence of isoprenaline (ISO, $10^{-5} \mathrm{M}, \mathrm{n}=6 ; \mathrm{K}_{\mathrm{c}}=20.9$, Intercept $\left.=3.1 * 10^{-9}\right)$. Data are means \pm S.E.M. $P<0.05$ : a ISO vs baseline.

et al. 2006). Although our main goal was to study the role of isoprenaline on diastolic properties, we did not observe an antagonist activity of KT against isoprenaline effects on inotropism and lusitropism, which is in line with previous studies (Gotoh 1995, Yatani et al. 1999). These studies suggested that $\beta$-adrenergic stimulation increases the peak L-type $\mathrm{Ca}^{2+}$ current via PKA-independent activation of $\mathrm{Ca}^{2+}$ channels (Yatani et al. 1999) or increases calcium leak from sarcoplasmatic reticulum via calcium/ calmodulin-dependent protein kinase (Curran et al. 2007). The effects of sustained $\beta_{1}$-adrenoceptor stimulation (inotropy, cell growth and cell death) are indeed primarily due to this latter pathway, rather than PKA signalling (Zhu et al. 2003, Wang et al. 2004). So, under certain physiological and pathological circumstances, this signaling pathway becomes more relevant (Singh et al. 2001, Xiao 2001).

Myocardial stiffness is determined both by cardiomyocytes' cytoskeleton and the extracellular matrix (Kass et al. 2004). Most of the elastic force of the cardiomyocytes is now thought to reside in the cytoskeletal protein, titin (Kruger and Linke 2009) which is known to be phosphorylated by PKA, PKG and PKC (Fukuda et al. 2005, Hidalgo et al. 2009, Kruger et al. 2009). Changes in its isoform composition and phosphorylation status have been shown to alter diastolic function and myocardial passive properties (Nagueh et al. 2004, Borbely et al. 2009). Based on this evidence, one of the possibilities that could explain our observations is that the acute decrease of stiffness induced by isoprenaline is associated with the modulation of titin's phosphorylation status by PKA, as
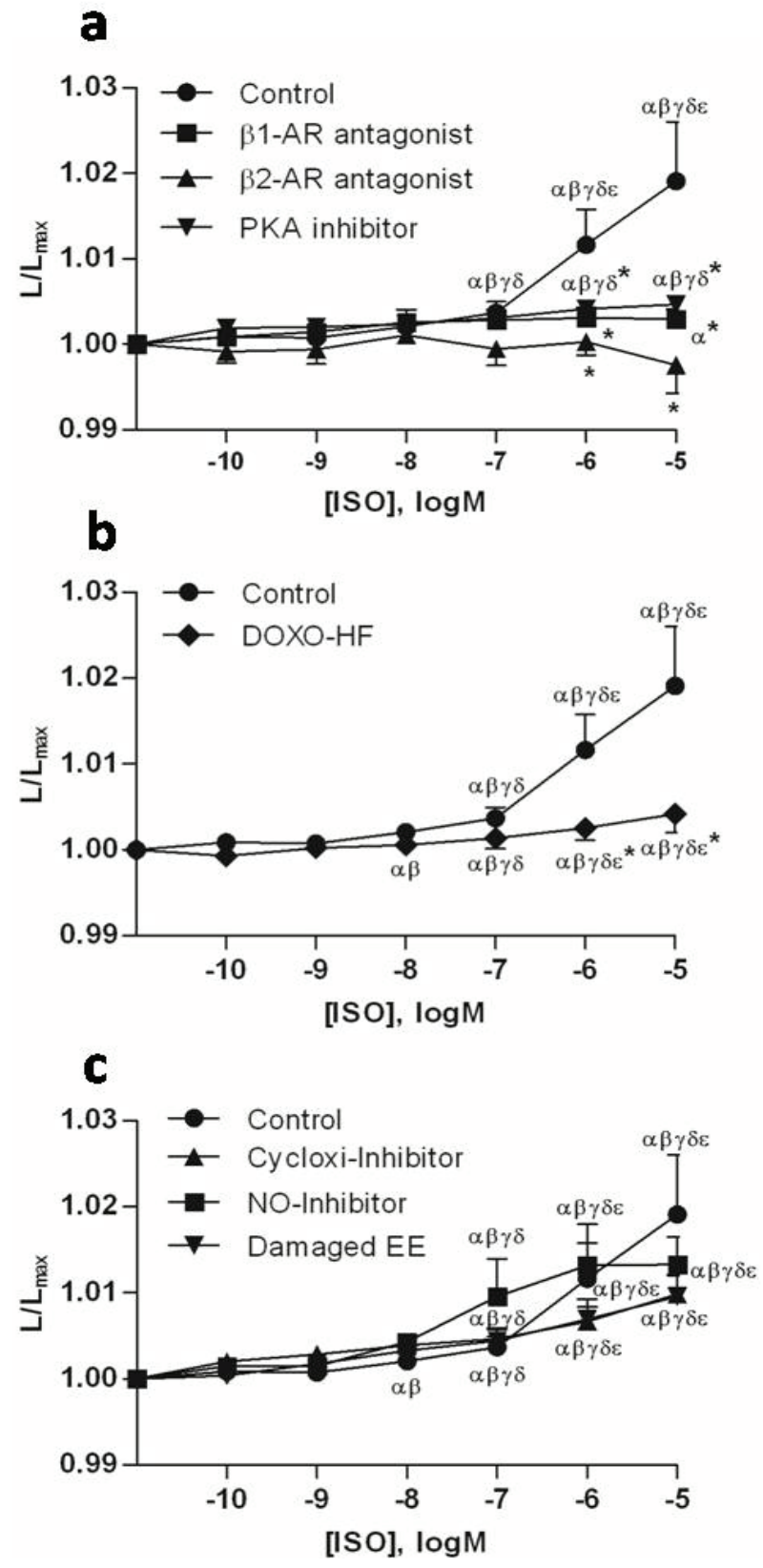

Fig. 4. Effects of increasing concentrations of isoprenaline (ISO, $10^{-10}$ to $\left.10^{-5} \mathrm{M} ; n=8\right)$ on passive muscle length $\left(L / L_{\max }\right):(a)$ in the absence (control; $n=13$ ) or presence of: a $\beta_{1}$-adrenoceptor antagonist (atenolol, 2.10 $\mathrm{M} ; \mathrm{n}=8$ ); a $\beta_{2}$-adrenoceptor antagonist (ICI, $10^{-6} \mathrm{M} ; \mathrm{n}=8$ ) or a PKA inhibitor (KT, $10^{-6} \mathrm{M}$; $\mathrm{n}=6) ;(\mathbf{b})$ in doxorubicin-induced heart failure group (DOXO-HF, $\mathrm{n}=9$ ); (c) in the presence of: damaged endothelial endothelium (TRX; $\mathrm{n=12}$ ); a NO synthase inhibitor, NG-Nitro-L-Arginine (L-NNA, $10^{-6} \mathrm{M} ; \mathrm{n}=7$ ) or a cyclooxygenase inhibitor, indomethacin (INDO, $10^{-6} \mathrm{M} ; \mathrm{n}=7$ ). Data are means \pm S.E.M., expressed as percent variation from baseline. $P<0.05$ : a vs baseline, $\beta$ vs $10^{-10}$ $\mathrm{M}$ ISO, y vs $10^{-9} \mathrm{M}$ ISO, $\delta$ vs $10^{-8} \mathrm{M}$ ISO, $\varepsilon$ vs $10^{-7} \mathrm{M}$ ISO and * $v s$ ISO alone.

demonstrated in the present study by its inhibition by KT.

The acute decrease of myocardial stiffness induced by isoprenaline was attenuated in DOX-treated rabbits, where $\beta$-adrenoceptor downregulation has been 


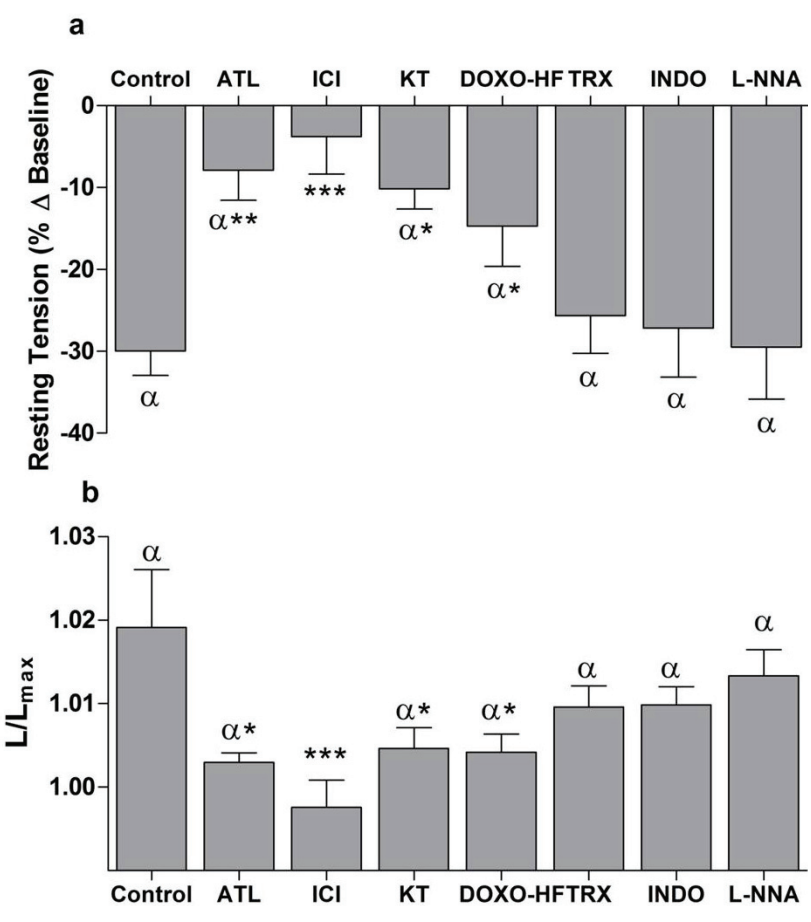

Fig. 5. Summary of the effects of isoprenaline (ISO, $10^{-5} \mathrm{M}$ ) on: (a) resting tension and (b) resting muscle length $\left(L / L_{\max }\right)$ in the absence (control, $n=13$ ) or presence of a $\beta_{1}$-adrenoceptor antagonist (atenolol, ATL, $2.10^{-5} \mathrm{M} ; \mathrm{n}=8$ ); a $\beta_{2}$-adrenoceptor antagonist (ICI, $10^{-6} \mathrm{M} ; \mathrm{n}=8$ ); a PKA inhibitor (KT, $\left.10^{-6} \mathrm{M}, \mathrm{n}=6\right)$; in doxorubicin-induced heart failure animals (DOXO-HF, $\mathrm{n}=9$ ); damaged endothelial endothelium (TRX, $\mathrm{n}=12)$; a NO synthase inhibitor, NG-Nitro-L-Arginine (L-NNA, $10^{-6} \mathrm{M} ; \mathrm{n}=7$ ); a cyclooxygenase inhibitor, indomethacin (INDO, $10^{-6} \mathrm{M}, \mathrm{n}=7$ ). Data are means \pm S.E.M., expressed as percent variation from baseline. $P<0.05$ : a vs baseline, $*$ vs control (ISO alone).

documented (Nagami et al. 1997, Kizaki et al. 2004). However, other factors can account for this effect such as a shift in titin isoform. In this regard, a compensatory shift from the stiff $\mathrm{N}_{2} \mathrm{~B}$ to the compliant $\mathrm{N}_{2} \mathrm{BA}$ isoform was described in patients with higher LV end-diastolic wall stress induced by dilated cardiomyopathy (Nagueh $e t$ al. 2004). Moreover, a smaller PKA-induced RT decrease was reported when the compliant N2BA titin isoform is phosphorylated rather than the stiff N2B isoform (Fukuda et al. 2005). We and others demonstrated an increase in LV-end-diastolic pressure and dilated cardiomyopathy in DOXO-HF rabbits (Nagami et al. 1997, Bras-Silva et al. 2007). Therefore, we could speculate that in DOX-treated rabbits a similar compensatory shift from N2B to the non-PKA sensitive N2BA isoform could have taken place during the course of HF progression explaining the attenuation of the isoprenaline-induced decrease of myocardial stiffness in dilated DOXO-HF hearts. Even though interesting, the confirmation of this aspect is beyond the scope of the present study and needs further investigation.
Another study of our group provided functional evidence of EE dysfunction in the DOXO-HF model (Bras-Silva and Leite-Moreira 2006). With regard to diastolic function, we have recently shown, in the same animal species, that the decrease of myocardial stiffness induced by ET-1 (Bras-Silva and Leite-Moreira 2006, Bras-Silva et al. 2008), urotensin II (Fontes-Sousa et al. 2007) and adrenomedullin (Fontes-Sousa et al. 2009) was dependent on EE and/or its mediators (NO and prostaglandins). Therefore, we performed other series of experimental protocols in order to confirm whether EE integrity is mandatory for isoprenaline-induced decrease on myocardial stiffness. In this set of studies, we found that although there was a clear trend towards a decrease of the isoprenaline-induced decrease of myocardial stiffness after removing the EE or upon inhibition of prostaglandins' release or NO synthase, none of these interventions was able per se to modify this effect.

\section{Conclusions}

Besides the well-known effects of $\beta$-adrenergic stimulation on myocardial contractility, the present study reveals that it acutely lowers myocardial stiffness. This novel effect, which requires the activation of $\beta_{1}$ and $\beta_{2-}$ adrenoceptor and is mediated by PKA, broadens our knowledge with regard to the acute neurohumoral modulation of diastolic function. This effect is of potential high physiological relevance as it might acutely decrease passive myocardial tension by as much as $30 \%$, allowing an intact heart to reach higher filling volumes at almost one third lower filling pressures. As this effect is abolished in the failing heart it might contribute to diastolic dysfunction in heart failure and therefore constitute a potential target for therapy. In this regard, these results highlight another possible important effect of $\beta$-blocker therapy in the treatment of HF.

\section{Conflict of Interest}

There is no conflict of interest.

\section{Acknowledgements}

The authors thank the excellent technical assistance of Marta Oliveira. This work was supported by the Portuguese Foundation for Science and Technology (grant nr. POCI/SAU-FCT/60803/2004, partially funded by FEDER and grant nr. PTDC/SAU-FCT/100442/2008, COMPETE, FEDER) through the Cardiovascular R\&D Unit (FCT nr. 51/94). There are no financial or other 
relations that could lead to a conflict of interests. Ana Patrícia Fontes-Sousa, Inês Falcão-Pires and Carmen Brás-Silva were supported by grants from the Portuguese Foundation for Science and Technology (nr.
SFRH/BD/22590/ 2005, nr. SFRH/BD/19538/2004, nr. SFRH/BPD/34568/2007 and Ciência 2008 Program, respectively).

\section{References}

ARNOLDA L, MCGRATH B, COCKS M, SUMITHRAN E, JOHNSTON C: Adriamycin cardiomyopathy in the rabbit: an animal model of low output cardiac failure with activation of vasoconstrictor mechanisms. Cardiovasc Res 19: 378-382, 1985.

BERS DM: Cardiac excitation-contraction coupling. Nature 415: 198-205, 2002.

BERS DM, GUO T: Calcium signaling in cardiac ventricular myocytes. Ann N Y Acad Sci 1047: 86-98, 2005.

BISHOPRIC NH, SATO B, WEBSTER KA: Beta-adrenergic regulation of a myocardial actin gene via a cyclic AMPindependent pathway. J Biol Chem 267: 20932-20936, 1992.

BORBELY A, FALCAO-PIRES I, VAN HEEREBEEK L, HAMDANI N, EDES I, GAVINA C, LEITE-MOREIRA AF, BRONZWAER JG, PAPP Z, VAN DER VELDEN J, STIENEN GJ, PAULUS WJ: Hypophosphorylation of the Stiff N2B titin isoform raises cardiomyocyte resting tension in failing human myocardium. Circ Res 104: 780786, 2009.

BORBELY A, VAN DER VELDEN J, PAPP Z, BRONZWAER JG, EDES I, STIENEN GJ, PAULUS WJ: Cardiomyocyte stiffness in diastolic heart failure. Circulation 111: 774-781, 2005.

BRAS-SILVA C, FONTES-SOUSA AP, MOURA C, AREIAS JC, LEITE-MOREIRA AF: Impaired response to ET(B) receptor stimulation in heart failure: functional evidence of endocardial endothelial dysfunction? Exp Biol Med (Maywood) 231: 893-898, 2006.

BRAS-SILVA C, LEITE-MOREIRA AF: Obligatory role of the endocardial endothelium in the increase of myocardial distensibility induced by endothelin-1. Exp Biol Med (Maywood) 231: 876-881, 2006.

BRAS-SILVA C, MONTEIRO-SOUSA D, DUARTE AJ, GUERRA M, FONTES-SOUSA AP, MOURA C, AREIAS JC, LEITE-MOREIRA AF: Nitric oxide and prostaglandins - important players in endothelin-1 induced myocardial distensibility. Physiol Res 57: 165-174, 2008.

BRISTOW MR, GINSBURG R, UMANS V, FOWLER M, MINOBE W, RASMUSSEN R, ZERA P, MENLOVE R, SHAH P, JAMIESON S, STINSON EB: Beta 1- and beta 2-adrenergic-receptor subpopulations in nonfailing and failing human ventricular myocardium: coupling of both receptor subtypes to muscle contraction and selective beta 1-receptor down-regulation in heart failure. Circ Res 59: 297-309, 1986.

BRODDE OE, BRUCK H, LEINEWEBER K: Cardiac adrenoceptors: physiological and pathophysiological relevance. $J$ Pharmacol Sci 100: 323-337, 2006.

BRONZWAER JG, PAULUS WJ: Matrix, cytoskeleton, or myofilaments: which one to blame for diastolic left ventricular dysfunction? Prog Cardiovasc Dis 47: 276-284, 2005.

BRUTSAERT DL, CLAES VA, SONNENBLICK EH: Velocity of shortening of unloaded heart muscle and the lengthtension relation. Circ Res 29: 63-75, 1971.

BRUTSAERT DL, MEULEMANS AL, SIPIDO KR, SYS SU: Effects of damaging the endocardial surface on the mechanical performance of isolated cardiac muscle. Circ Res 62: 358-366, 1988.

CURRAN J, HINTON MJ, RIOS E, BERS DM, SHANNON TR: Beta-adrenergic enhancement of sarcoplasmic reticulum calcium leak in cardiac myocytes is mediated by calcium/calmodulin-dependent protein kinase. Circ Res 100: 391-398, 2007.

FAUCHER FA, GANNIER FE, LIGNON JM, COSNAY P, MALECOT CO: Roles of PKA, PI3K, and cPLA2 in the NO-mediated negative inotropic effect of $\beta_{2}$-adrenoceptor agonists in guinea pig right papillary muscles. $\mathrm{Am} \mathrm{J}$ Physiol Cell Physiol 294: C106-C117, 2008.

FENTZKE RC, BUCK SH, PATEL JR, LIN H, WOLSKA BM, STOJANOVIC MO, MARTIN AF, SOLARO RJ, MOSS RL, LEIDEN JM: Impaired cardiomyocyte relaxation and diastolic function in transgenic mice expressing slow skeletal troponin I in the heart. J Physiol Lond 517: 143-157, 1999. 
FONTES-SOUSA AP, BRAS-SILVA C, PIRES AL, MONTEIRO-SOUSA D, LEITE-MOREIRA AF: Urotensin II acutely increases myocardial length and distensibility: potential implications for diastolic function and ventricular remodeling. Naunyn Schmiedebergs Arch Pharmacol 376: 107-115, 2007.

FONTES-SOUSA AP, PIRES AL, CARNEIRO CS, BRAS-SILVA C, LEITE-MOREIRA AF: Effects of adrenomedullin on systolic and diastolic myocardial function. Peptides 30: 796-802, 2009.

FUKUDA N, WU Y, NAIR P, GRANZIER HL: Phosphorylation of titin modulates passive stiffness of cardiac muscle in a titin isoform-dependent manner. J Gen Physiol 125: 257-271, 2005.

GOTOH H: Phosphorylation and adrenergic chronotropism and inotropism in guinea pig cardiac muscles. Life Sci 56: 1655-1663, 1995.

GRUEN M, PRINZ H, GAUTEL M: cAPK-phosphorylation controls the interaction of the regulatory domain of cardiac myosin binding protein C with myosin-S2 in an on-off fashion. FEBS Lett 453: 254-259, 1999.

HAIKALA H, KAHEINEN P, LEVIJOKI J, LINDEN IB: The role of cAMP- and cGMP-dependent protein kinases in the cardiac actions of the new calcium sensitizer, levosimendan. Cardiovasc Res 34: 536-546, 1997.

HIDALGO C, HUDSON B, BOGOMOLOVAS J, ZHU Y, ANDERSON B, GREASER M, LABEIT S, GRANZIER H: PKC phosphorylation of titin's PEVK element: a novel and conserved pathway for modulating myocardial stiffness. Circ Res 105: 631-638, 2009.

IWAI-KANAI E, HASEGAWA K, ARAKI M, KAKITA T, MORIMOTO T, SASAYAMA S: Alpha- and betaadrenergic pathways differentially regulate cell type-specific apoptosis in rat cardiac myocytes. Circulation 100: 305-311, 1999.

JOHNS EC, SIMNETT SJ, MULLIGAN IP, ASHLEY CC: Troponin I phosphorylation does not increase the rate of relaxation following laser flash photolysis of diazo-2 in guinea-pig skinned trabeculae. Pflugers Arch 433: 842$844,1997$.

KASS DA, BRONZWAER JG, PAULUS WJ: What mechanisms underlie diastolic dysfunction in heart failure? Circ Res 94: 1533-1542, 2004.

KIEHN J, KARLE C, THOMAS D, YAO X, BRACHMANN J, KUBLER W: HERG potassium channel activation is shifted by phorbol esters via protein kinase A-dependent pathways. J Biol Chem 273: 25285-25291, 1998.

KIZAKI K, AKATSUKA K, MOMOZAKI M, FUJIMORI Y, UCHIDE T, TEMMA K, HARA Y: Changes in myocardial beta1-adrenergic receptor and stimulatory G-protein gene expression after chronic treatment with doxorubicin in rat. J Vet Med Sci 66: 989-992, 2004.

KRUGER M, KOTTER S, GRUTZNER A, LANG P, ANDRESEN C, REDFIELD MM, BUTT E, DOS REMEDIOS CG, LINKE WA: Protein kinase G modulates human myocardial passive stiffness by phosphorylation of the titin springs. Circ Res 104: 87-94, 2009.

KRUGER M, LINKE WA: Titin-based mechanical signalling in normal and failing myocardium. J Mol Cell Cardiol 46: 490-498, 2009.

KUNST G, KRESS KR, GRUEN M, UTTENWEILER D, GAUTEL M, FINK RH: Myosin binding protein C, a phosphorylation-dependent force regulator in muscle that controls the attachment of myosin heads by its interaction with myosin S2. Circ Res 86: 51-58, 2000.

LEITE-MOREIRA AF: Current perspectives in diastolic dysfunction and diastolic heart failure. Heart 92: 712-718, 2006.

LEITE-MOREIRA AF, BRAS-SILVA C: Inotropic effects of $\mathrm{ET}_{\mathrm{B}}$ receptor stimulation and their modulation by endocardial endothelium, NO, and prostaglandins. Am J Physiol Heart Circ Physiol 287: H1 194-H1 199, 2004.

LEITE-MOREIRA AF, BRAS-SILVA C, PEDROSA CA, ROCHA-SOUSA AA: ET-1 increases distensibility of acutely loaded myocardium: a novel $\mathrm{ET}_{\mathrm{A}}$ and $\mathrm{Na}^{+} / \mathrm{H}^{+}$exchanger-mediated effect. Am J Physiol Heart Circ Physiol 284: H1332-H1339, 2003.

LEITE-MOREIRA AF, CASTRO-CHAVES P, PIMENTEL-NUNES P, LIMA-CARNEIRO A, GUERRA MS, SOARES JB, FERREIRA-MARTINS J: Angiotensin II acutely decreases myocardial stiffness: a novel AT1, PKC and $\mathrm{Na}^{+} / \mathrm{H}^{+}$exchanger-mediated effect. Br J Pharmacol 147: 690-697, 2006.

LEITE-MOREIRA AF, CORREIA-PINTO J, HENRIQUES-COELHO T: Interaction between load and beta-adrenergic stimulation in the modulation of diastolic function (in Portugese). Rev Port Cardiol 20: 57-62, 2001.

MARIAN AJ: Beta-adrenergic receptors signaling and heart failure in mice, rabbits and humans. J Mol Cell Cardiol 41: 11-13, 2006. 
MAURICE JP, SHAH AS, KYPSON AP, HATA JA, WHITE DC, GLOWER DD, KOCH WJ: Molecular beta-adrenergic signaling abnormalities in failing rabbit hearts after infarction. Am J Physiol 276: H1853-H1860, 1999.

MOHAN P, BRUTSAERT DL, SYS SU: Myocardial performance is modulated by interaction of cardiac endothelium derived nitric oxide and prostaglandins. Cardiovasc Res 29: 637-640, 1995.

NAGAMI K, YOSHIKAWA T, SUZUKI M, WAINAI Y, ANZAI T, HANDA S: Abnormal beta-adrenergic transmembrane signaling in rabbits with adriamycin-induced cardiomyopathy. Jpn Circ J 61: 249-255, 1997.

NAGUEH SF, SHAH G, WU Y, TORRE-AMIONE G, KING NM, LAHMERS S, WITT CC, BECKER K, LABEIT S, GRANZIER HL: Altered titin expression, myocardial stiffness, and left ventricular function in patients with dilated cardiomyopathy. Circulation 110: 155-162, 2004.

PAULUS WJ, VANTRIMPONT PJ, SHAH AM: Acute effects of nitric oxide on left ventricular relaxation and diastolic distensibility in humans. Assessment by bicoronary sodium nitroprusside infusion. Circulation 89: 2070-2078, 1994.

ROBERTSON SP, JOHNSON JD, HOLROYDE MJ, KRANIAS EG, POTTER JD, SOLARO RJ: The effect of troponin I phosphorylation on the $\mathrm{Ca}^{2+}$-binding properties of the $\mathrm{Ca}^{2+}$-regulatory site of bovine cardiac troponin. $J$ Biol Chem 257: 260-263, 1982.

SHAH AM, MACCARTHY PA: Paracrine and autocrine effects of nitric oxide on myocardial function. Pharmacol Ther 86: 49-86, 2000.

SINGH K, XIAO L, REMONDINO A, SAWYER DB, COLUCCI WS: Adrenergic regulation of cardiac myocyte apoptosis. J Cell Physiol 189: 257-265, 2001.

STEINBERG SF: The molecular basis for distinct beta-adrenergic receptor subtype actions in cardiomyocytes. Circ Res 85: 1101-1111, 1999.

VAN HEEREBEEK L, BORBELY A, NIESSEN HW, BRONZWAER JG, VAN DER VELDEN J, STIENEN GJ, LINKE WA, LAARMAN GJ, PAULUS WJ: Myocardial structure and function differ in systolic and diastolic heart failure. Circulation 113: 1966-1973, 2006.

VARMA DR, SHEN H, DENG XF, PERI KG, CHEMTOB S, MULAY S: Inverse agonist activities of beta-adrenoceptor antagonists in rat myocardium. Br J Pharmacol 127: 895-902, 1999.

WANG W, ZHU W, WANG S, YANG D, CROW MT, XIAO RP, CHENG H: Sustained beta1-adrenergic stimulation modulates cardiac contractility by $\mathrm{Ca}^{2+} /$ calmodulin kinase signaling pathway. Circ Res 95: 798-806, 2004.

WATTANAPERMPOOL J, GUO X, SOLARO RJ: The unique amino-terminal peptide of cardiac troponin I regulates myofibrillar activity only when it is phosphorylated. J Mol Cell Cardiol 27: 1383-1391, 1995.

XIAO RP: Beta-adrenergic signaling in the heart: dual coupling of the $\beta_{2}$-adrenergic receptor to G(s) and G(i) proteins. Sci STKE 2001: re15, 2001.

XIAO RP, JI X, LAKATTA EG: Functional coupling of the $\beta_{2}$-adrenoceptor to a pertussis toxin-sensitive $\mathrm{G}$ protein in cardiac myocytes. Mol Pharmacol 47: 322-329, 1995.

YATANI A, TAJIMA Y, GREEN SA: Coupling of beta-adrenergic receptors to cardiac L-type $\mathrm{Ca}^{2+}$ channels: preferential coupling of the $\beta_{1}$ versus $\beta_{2}$ receptor subtype and evidence for PKA-independent activation of the channel. Cell Signal 11: 337-342, 1999.

ZHANG R, ZHAO J, MANDVENO A, POTTER JD: Cardiac troponin I phosphorylation increases the rate of cardiac muscle relaxation. Circ Res 76: 1028-1035, 1995.

ZHU WZ, WANG SQ, CHAKIR K, YANG D, ZHANG T, BROWN JH, DEVIC E, KOBILKA BK, CHENG H, XIAO RP: Linkage of $\beta_{1}$-adrenergic stimulation to apoptotic heart cell death through protein kinase A-independent activation of $\mathrm{Ca}^{2+} /$ calmodulin kinase II. $J$ Clin Invest 111: 617-625, 2003.

ZIMMERMANN WH, SCHNEIDERBANGER K, SCHUBERT P, DIDIE M, MUNZEL F, HEUBACH JF, KOSTIN S, NEUHUBER WL, ESCHENHAGEN T: Tissue engineering of a differentiated cardiac muscle construct. Circ Res 90: 223-230, 2002. 